\title{
Analysis of high temperature gasdynamics in a rectangular channel using a coupled core-boundary layer model
}

\author{
P SATYAMURTHY, RAJENDRA* and V K ROHATGI \\ Plasma Physics Division, Bhabha Atomic Research Centre, Bombay \\ 400085 , India \\ *Physics Department, Carmel College, Goa, India \\ MS received 29 October 1985; revised 18 September 1986
}

\begin{abstract}
In this paper two-dimensional steady state compressible, turbulent boundary layer equations along with the core are solved for a channel of rectangular cross-section. The behaviour of core velocity, core temperature, pressure profile, friction coefficient and heat flow for different mass flow rates and inlet pressures are analysed for combustion gases. The results are compared with experimental results obtained on ZINC (zero induction channel) during the commissioning of the MHD plant at Tiruchirapalli. The results match the theoretical predictions quite well.
\end{abstract}

Keywords. Rectangular channel; high temperature gas dynamics; quasi-three-dimensional model; turbulent compressible boundary layer; MHD generator.

\section{Introduction}

This paper presents the gasdynamic analysis of high temperature gases in a diverging rectangular channel. The primary motivation for such a study arises from the flow of seeded combustion products in (magnetohydrodynamics) MHD generators (Rohatgi \& Venkatramani 1981).

An MHD pilot plant is being set up at Tiruchirapalli under the Indian MHD programme sponsored by the Department of Nonconventional Energy Sources, and is currently being commissioned. During this phase of initial trials the active MHD channel is replaced by a Zero Induction Channel (ZINC) which is similar to the MHD channel in cross-section. This channel, $5.2 \mathrm{~m}$ long, is rectangular in cross-section and has a diverging angle through most of its length. Hence, it was decided to take up this channel for investigation.

The flow in this channel is assumed to be turbulent and compressible. The model is basically a hydrodynamic coupled core-boundary layer flow (Satyamurthy et al 1982). The equations of conservation of mass, momentum and energy are solved by the Patankar-Spalding implicit difference technique (Patankar \& Spalding 1967). 
During the operation of the MHD plant, cold air is initially passed through the system. Then the air preheater is switched on and hot air up to a temperature of $1500^{\circ} \mathrm{C}$ is passed through the system. After stabilization, fuel and finally seed are introduced until the required composition of gas/plasma is obtained. The schematic diagram of the MHD plant is shown in figure 1. The figure also identifies the systems which have been used during the first run. All the results presented in this paper pertain to plasma flow conditions.

It was observed by analysis that the flow becomes fully developed at a distance of $1.5 \mathrm{~m}$ from the nozzle. Since the initial section of the channel is subjected to maximum thermal and gasdynamic stresses, the analysis was confined to the initial $1.5 \mathrm{~m}$ where the flow is not fully developed.

The analysis includes determination of temperature, heat flux, velocity, Mach number, pressure and friction coefficient for various inlet parameters. Some of the theoretically predicted values have been compared with experimental results.

\section{Mathematical modelling}

This model is basically a hydrodynamic coupled core-boundary layer flow. The plasma is assumed to be in thermodynamic equilibrium. It is also assumed to be non-ideal and all the thermodynamic and transport parameters (enthalpy,

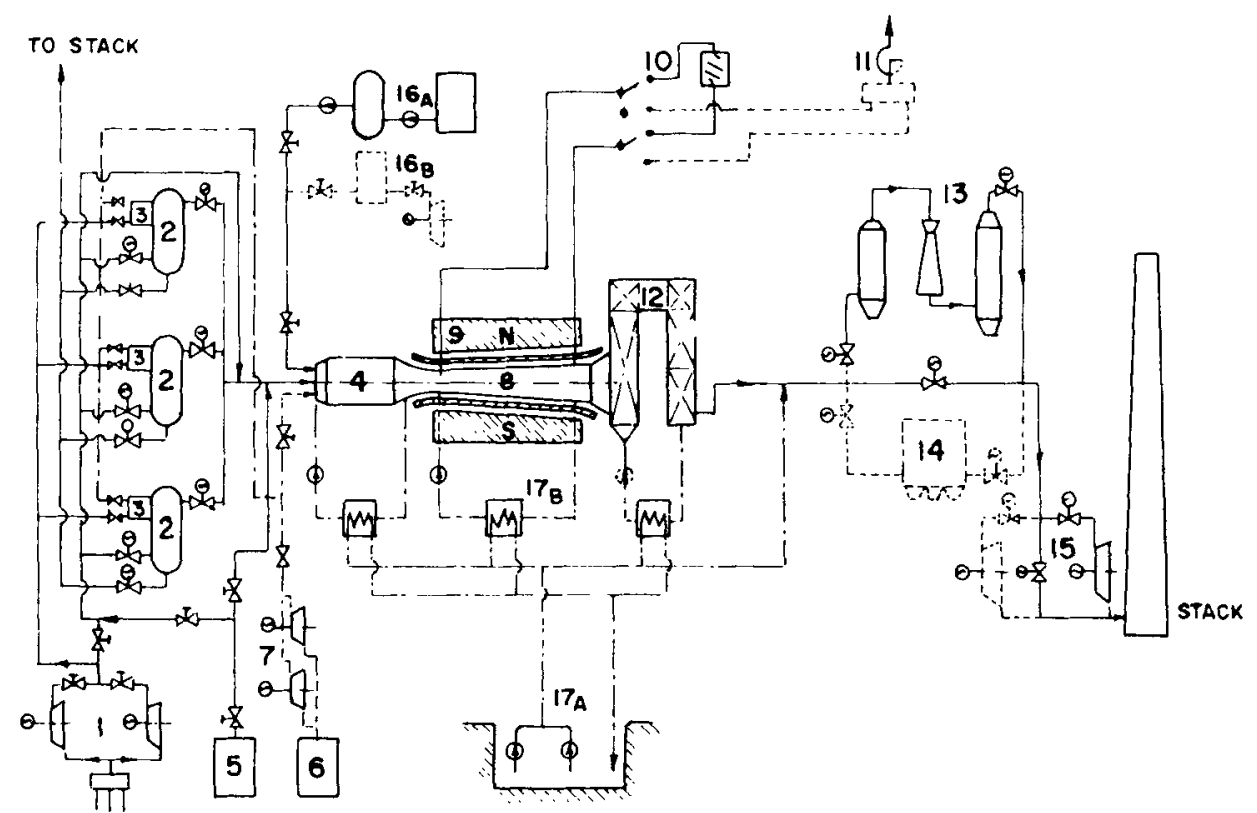

Figure 1. Schematic of the plant for the first experimental run. (Items $2,3,9,10,11,12,14,15,16 \mathrm{~B}$ have been by-passed during this run.) 1 -air compressors; 2 - air preheaters; 3 - air preheater combustor; 4 - main combustor; 5 - oxygen plant; 6 - water gas plant; 7 - gas compressors; 8 - MHD channel; 9 - electromagnet; 10 - Ohmic load; 11 - Inverter: 12 - model steam generator; 13 - wetseed recovery: 14 -dryseed recovery; 15 - exhausters: 16A-seed solution injection; 16B - dry seed injection; $17 \mathrm{~A}$ - technical water cooling system; 17B-chemically purified water cooling system. 
density etc.) are determined as functions of pressure and temperature (Das 1979). The combustion products are obtained by burning blue water gas with $40-60 \%$ oxygen enriched air seeded with $50 \%$ aqueous potassium carbonate solution.

The plasma flow equations consist of global conservation equations for mass, momentum and energy. In general, the equations are three-dimensional but can be approximated to one-dimensional in the core and two-dimensional in the boundary layers. The flow is taken to be steady, compressible and turbulent. The eddy viscosity model is used to account for the turbulence (Schlichting 1968).

The flow cross section is divided into three regions i.e. core, boundary layers and corners as shown in figure 2 . Since the maximum thermal and gasdynamic stresses are present only upto the region where the flow is not fully developed (i.e. the two opposite boundary layers not merging with each other), the analysis is confined only upto the length of the channel where the flow is not fully developed.

The corners of a rectangular channel are more difficult to model due to the three-dimensional nature of the flow. However, they occupy a very small region compared to the overall channel cross-section. In this model, the corners are absorbed in one of the boundary layers while determining the total mass flow rate in the channel.

It is also assumed that for the ZINC channel, all the four boundary layers are identical because of identical construction and identical wall boundary conditions. Hence it is sufficient to analyse only one boundary layer region. The total effect of all the boundary layers can be obtained by suitable multiplying factors. The coordinate system used is also shown in figure 2.

\subsection{Plasma flow equations}

2.1a Core region: The equations are based on the assumption that transverse variation of fluid property is negligible. Under this assumption viscous and heat transfer effects become negligible. The variables are functions of $x$ only.

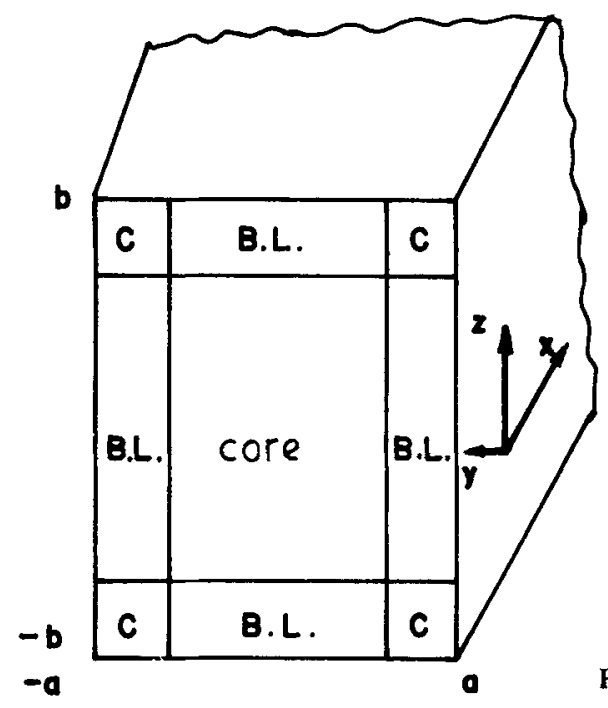

Figure 2. Flow cross-section and coordinates used. 
Momentum equation

$$
\rho U(\mathrm{~d} U / \mathrm{d} x)=-\mathrm{d} P / \mathrm{d} x .
$$

Energy equation

$$
\rho U(\mathrm{~d} H / \mathrm{d} x)=0 .
$$

$\rho, U, P$ and $H$ are density, velocity along $x$, pressure and total enthalpy of the plasma, respectively.

2.1b Boundary layer region: Under the boundary layer approximation the equations are two-dimensional and the different variables are functions of $x$ and $y$ (or $z$ ) only. All four boundary layers are identical for the test channel considered. Here the boundary equations for the side walls are presented. Similar equations with respect to $x$ and $z$ can be obtained for the upper and the lower walls.

\section{Continuity equation}

$$
(\partial \rho U / \partial x)+(\partial \rho V / \partial y)=0
$$

$V$ is the velocity in the $y$ direction.

\section{Momentum equation}

$$
\rho U \frac{\partial U}{\partial x}+\rho V \frac{\partial V}{\partial y}=-\frac{\mathrm{d} P}{\mathrm{~d} x}+\frac{\partial}{\partial y}\left\{(\mu+\varepsilon) \frac{\partial U}{\partial y}\right\},
$$

$\mu$ is the molecular viscosity and $\varepsilon$ is the eddy viscosity due to turbulence and is given by

$$
\varepsilon=\rho l^{2}|\partial U / \partial y|
$$

where $l$ is the Prandtl mixing length which can be determined as follows (Patankar \& Spalding 1967) with:

and with

$$
0<y<\lambda y_{l} / k, \text { then } l=k y,
$$

$$
\lambda y_{l} / k<y_{l}, \text { then } l=\lambda y_{l},
$$

where $\lambda$ and $k$ are constants and are taken as 0.09 and 0.0435 respectively. $y_{l}$ is the characteristic thickness of the boundary layer.

Energy equation

$$
\begin{aligned}
\rho U \frac{\partial H}{\partial x}+ & \rho V \frac{\partial H}{\partial y}=\frac{\partial}{\partial y}\left\{\left(\frac{\mu}{P_{l}}+\frac{\varepsilon}{P_{T}}\right) \frac{\partial H}{\partial y}\right\} \\
& +\frac{\partial}{\partial y}\left[\left\{\mu\left(1-\frac{1}{P_{l}}\right)+\varepsilon\left(1-\frac{1}{P_{T}}\right)\right\} \frac{\partial U^{2} / 2}{\partial y}\right]
\end{aligned}
$$


$F_{l}$ is the laminar Prandtl number and $P_{T}$ is the turbulent Prandtl number. $P_{T}$ is defined to account for heat transfer due to turbulence.

$$
P_{T} \equiv \varepsilon C_{P} / K_{T}=0.9
$$

where $C_{P}$ is specific heat of plasma and $K_{T}$ is the effective thermal conductivity due to turbulence.

2.1c Total conservation of mass: All regions of the flow are coupled by the total mass conservation

$$
G=\int_{-a}^{a} \int_{-b}^{b} \rho U \mathrm{~d} y \mathrm{~d} z
$$

where $G$ is the total mass flow rate in the channel.

\subsection{Numerical technique}

The boundary layer equations are coupled, non-linear parabolic equations. These equations are solved numerically by the Patankar and Spalding technique. For channels with specified area of cross-section the determination of the pressure gradient is complicated due to the presence of boundary layers. It is essential to predict the pressure accurately because error can lead to an unrealistic channel analysis. This is overcome by the following method. Assuming that the shape of profiles of velocity, density and other variables in the boundary layers at downstream points do not change appreciably, an expression for pressure can be obtained as follows (Satyamurthy et al 1982).

$$
\frac{\mathrm{d} P}{\mathrm{~d} x}=\left(-\frac{F}{A}+\frac{G \bar{U}}{A^{2}} \frac{\mathrm{d} A}{\mathrm{~d} x}-\frac{G \bar{U}}{A \bar{T}} \frac{\mathrm{d} \bar{T}}{\mathrm{~d} x}\right) /\left(1-\frac{G \bar{U}}{A P}\right)
$$

where $\bar{U}$ is given by

$$
\bar{U}=\int_{-a}^{a} \int_{-b}^{b} \rho U^{2} \mathrm{~d} y \mathrm{~d} z / \int_{-a}^{a} \int_{-b}^{b} \rho U \mathrm{~d} y \mathrm{~d} z .
$$

$F$ is the frictional force per unit length due to the four walls of the channel and is given by

$$
F=2 \tau(2 a+2 b)
$$

$\tau$ is the shear stress and is given by

$$
\tau=\mu \mathrm{d} U /\left.\mathrm{d} y\right|_{\text {wall }}=\mu \mathrm{d} U /\left.\mathrm{d} z\right|_{\text {wall }} .
$$


Due to various approximations made, the pressure gradient calculated using the above expression may lead to slight error which corresponds to a different cross-sectional area. In order to correct this error the area variation term is determined as below:

$$
\mathrm{d} A / \mathrm{d} x=\left[\left(A_{I}-A_{U}\right) /\left(x_{I}-x_{U}\right)\right]+\left[\left(A_{U}-A_{U}^{\prime}\right) /\left(x_{D}-x_{U}\right)\right] .
$$

The subscripts $U$ and $D$ correspond to the upstream and the downstream points respectively. $A_{U}^{\prime}$ refers to the area occupied by the fluid at the upstream point. The first term on the right hand side corresponds to the real change in area variation. The second term which is zero in an ideal condition arises due to the error in the pressure predicted at the upstream. Thus by including this term the error present at the upstream point is compensated at the downstream. This avoids iteration and saves excess computer time.

\subsection{Boundary conditions}

For solving core and boundary layer equations the following values at the entrance as well as along the channel have to be specified.

(i) At the entrance $(x=0)$, (a) static pressure, $P$, (b) static temperature of the core, $T$, (c) plasma flow rate (mass flow rate), $G$, (d) boundary layer thickness, $\delta$.

(ii) Along the channel, (a) wall temperature, $T_{w}$, (b) channel cross-sectional area A.

\subsection{Method of solution}

The parabolic type of boundary layer equations requires the specification of initial values of the dependent variables across the boundary layer and as well as along the channel wall and core. In addition to this, the upstream values should be known while evaluating the downstream values.

2.4a Initial profile determination: At the entrance of the channel, initial velocity and enthalpy profiles in the boundary layers are necessary. These are determined as follows.

Plasma density and static enthalpy are calculated from pressure and temperature using the tables (Das 1979). The core velocity is calculated from the conservation of mass flow rate and neglecting the boundary layer as follows:

$$
U_{C}=G / \rho_{C} A \text {. }
$$

The boundary layers can be neglected at the entrance as they occupy a very small area compared to the core $(\ll 1 \%)$. Once the velocity is known the velocity profiles in the boundary can be determined using $1 / 7$ th power law profile for turbulent flow (Cebeci 1974).

The stagnation enthalpy in the core $H_{C}$ and at the wall $H_{W}$ are determined from static enthalpy, core velocity and wall temperature. The stagnation enthalpy at any point in the boundary layer is determined based on Crocco's solution (Cebeci 1974),

$$
\left(H-H_{W}\right) /\left(H_{C}-H_{W}\right)=\left(U / U_{C}\right)^{1 / 7},
$$

subscripts $C$ and $W$ corresponding to core and wall respectively. 
2.4b Calculations along the channel: Along $x$, the step length is chosen such that it is half the thickness of the boundary layer at the upstream point. To solve the equation of the downstream, some of the upstream values, the boundary conditions, and the parameters which give the source terms are required. The pressure gradient is determined using (9). The core solutions for velocity and enthalpy are

and

$$
\left.U_{l}=\left\{U_{U^{\prime}}^{2}+2(\mathrm{~d} P / \mathrm{d} x)\left(x_{l}\right)-x_{L^{\prime}}\right) / \rho\right\}^{12}
$$

$$
H_{l}=H_{l}
$$

The temperature of the gas is determined throughout the cross-section of the channel using enthalpy $(P, T)$ tables. The process is repeated till the flow is fully developed.

\section{Results and analysis}

In this section the detailed plasma flow and the thermal analysis conducted on the zero induction MIID channel (ZINC) are presented. Even though analysis is conducted for hot air as well, only combustion plasma data are presented in this paper.

The internal dimensions of the ZINC is identical to the MHD generator and consists of five parts, viz, nozzle spacer, channel, channel spacer, diffuser spacer and diffuser with a total length of $5.2 \mathrm{~m}$. Figure 3 gives the schematic of the ZINC system. The analysis on ZINC is carried out only upto a length of $1.5 \mathrm{~m}$ from the nozzle because it was determined by calculations that the boundary layer becomes fully developed beyond that. The length $1.5 \mathrm{~m}$ corresponds to the nozzle spacer and most of the channel. Figure 4 gives the photograph of the ZINC system.

A number of parametric studies were conducted for ZINC with this model. Some results are presented here. The range of parameters that :re possible in the Tiruchi pilot plant is presented in table 1 .

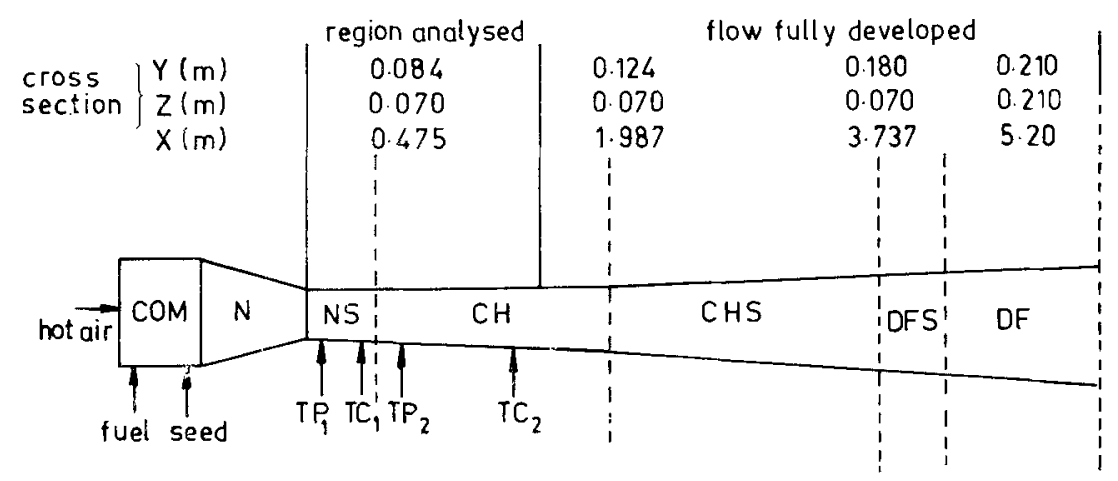

Figure 3. Schematic flow train of the pilot plant. COM: combustor; N: nozzle; NS: nozzle spacer; CH: channel: CHS: channel spacer: DF: diffuser; $\mathrm{DFS}$ : diffusion spacer; $\mathrm{TC}_{1}, \mathrm{TC}_{2}$ : location of wall temperature measurcments; $T P_{1}, T P_{2}$ : location of gas temperature measurements. 


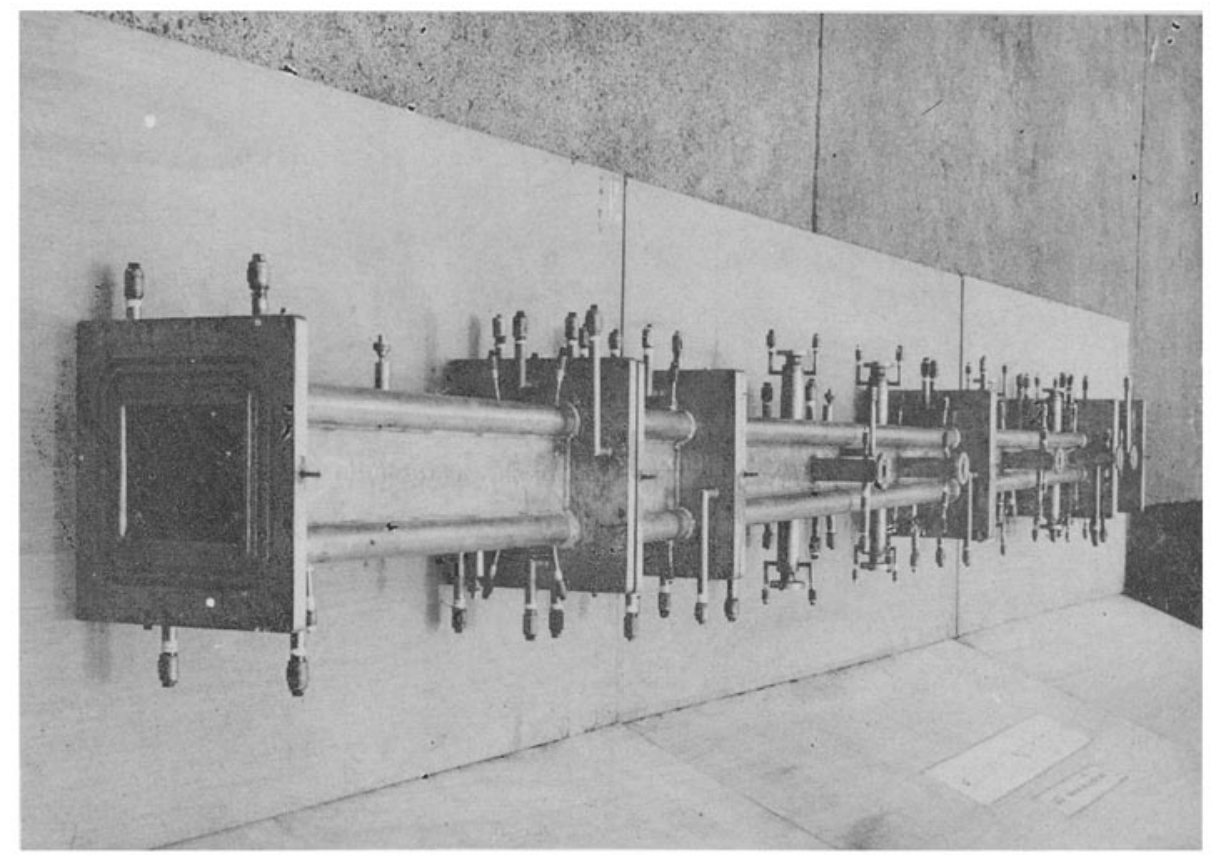

Figure 4. The ZINC channel.

\subsection{Gasdynamic parameters}

3.1a Supersonic flow region: It is found that for some combination of inlet parameters (low pressure and high mass flow rates) the core velocity is supersonic and no analysis is done for these cases. In figure 5 the regions of subsonic and supersonic flow are shown for combustion plasma. It can be seen from the figures

Table 1. Specifications of the Indian MHD facility

\begin{tabular}{|c|c|c|}
\hline & $\begin{array}{l}\text { Nominal } \\
\text { parameters }\end{array}$ & $\begin{array}{l}\text { Parameters for } \\
\text { first run }\end{array}$ \\
\hline Fuel & $\mathrm{BWG}^{*}$ & BWG \\
\hline Oxidizer & $\begin{array}{l}\text { Air with } 40 \% \\
\mathrm{O}_{2} \text { enrichment } \\
\text { (by weight) }\end{array}$ & $\begin{array}{l}\text { Air upto } 60 \%{ }^{\dagger} \\
\mathrm{O}_{2} \text { enrichment } \\
\text { (by weight) }\end{array}$ \\
\hline $\begin{array}{l}\text { Oxidizer temperature at } \\
\text { inlet of combustion } \\
\text { chamber }\end{array}$ & Upto $1500^{\circ} \mathrm{C}$ & Upto $1000^{\circ} \mathrm{C}$ \\
\hline $\begin{array}{l}\text { Plasma flow rate of } \\
\text { combustion products }\end{array}$ & $1 \mathrm{~kg} / \mathrm{s}$ & $0.3 \mathrm{~kg} / \mathrm{s}^{\dagger}$ \\
\hline $\begin{array}{l}\text { Pressure }^{* *} \text { in combustion } \\
\text { chamber }\end{array}$ & Upto $3 \mathrm{~atm}^{\ddagger}$ & $1 \mathrm{~atm}$ \\
\hline Velocity in the channel & $800 \mathrm{~m} / \mathrm{s}$ & $200 \mathrm{~m} / \mathrm{s}$ \\
\hline
\end{tabular}

${ }^{*}$ Blue water gas; ${ }^{+}$auxiliary system constraints;

${ }^{*}$ atm $=1 \cdot 0133 \times 10^{5} \mathrm{~Pa} .{ }^{* *}$ All pressures given are absolute pressures. 


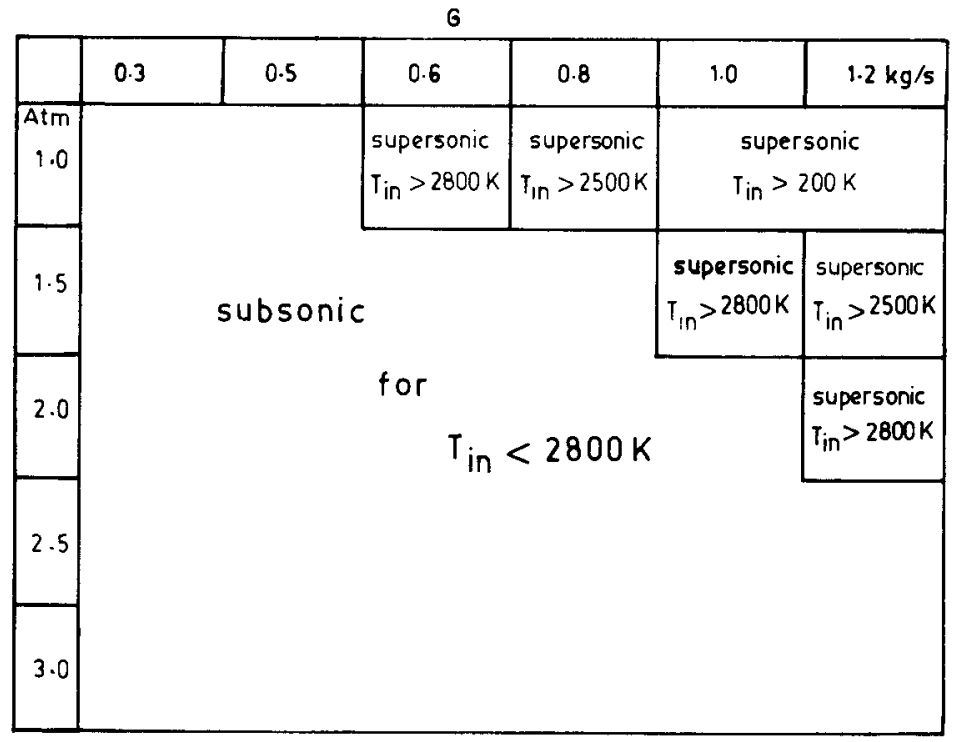

Figure 5. Flow hehaviour for different pressures, temperatures and mass flow rates at the inlet.

that for mass flow rates upto $0.5 \mathrm{~kg} / \mathrm{s}$ the flow is subsonic for all the pressures and temperatures.

3.1b Core velocity: In figure 6 , for typical inlet parameters, the core velocity $(U)$ and the Mach number $(M)$ are plotted $(M=$ core velocity/velocity of sound). We see that the velocity (represented by $U$ ) on the curve increases slightly upto a length of $0.475 \mathrm{~m}$ along the channel and decreases afterwards. This is because upto $0.475 \mathrm{~m}$ the cross-section of the channel (nozzle spacer) remains constant and beyond that cross-sectional area increases along the channel. Hence the velocity decreases $(\rho u A=G=$ constant). The decrease in velocity is reflected in Mach number also. Table 2 shows the core velocity along the channel for various mass flow rates for a given inlet pressure and inlet temperature. We find the maximum velocity around $730 \mathrm{~m} / \mathrm{s}$ for a pressure of $2.5 \mathrm{~atm}$ at the inlet even for a mass flow

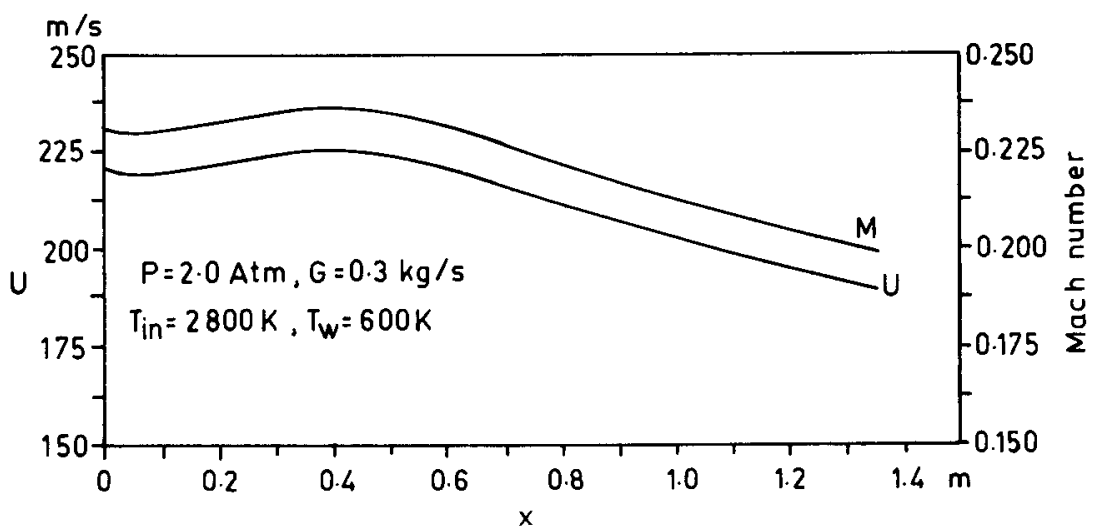

Figure 6. Velocity and Mach number along the channel. 
Table 2. Velocity along the channel for different mass flow rates for combustion plasma

\begin{tabular}{|c|c|c|c|c|c|c|}
\hline \multirow{2}{*}{$\begin{array}{c}x \\
(\mathrm{~m})\end{array}$} & \multicolumn{6}{|c|}{ Velocity $(\mathrm{m} / \mathrm{s})$ along the channel for $G=(\mathrm{kg} / \mathrm{s})$} \\
\hline & 01.3 & 0.5 & $0 \cdot 6$ & 0.8 & $1 \cdot 0$ & $1 \cdot 2$ \\
\hline $0 \cdot()$ & 174 & 292 & 350 & 468 & 588 & 710 \\
\hline $0 \cdot 1$ & 175 & 290) & 350 & 465 & 582 & $70) 2$ \\
\hline 0.2 & 177 & 292 & 353 & 468 & 590 & 712 \\
\hline 0.3 & 178 & 297 & 355 & 468 & 594 & 720 \\
\hline 0.4 & 178 & 298 & 356 & 468 & 598 & 726 \\
\hline 0.5 & 177 & 297 & 355 & 467 & 584 & 722 \\
\hline 0.6 & 175 & 290 & 348 & 465 & 567 & 695 \\
\hline 0.7 & 171 & 284 & 340 & 451 & 560 & 662 \\
\hline 0.8 & 167 & 276 & 332 & 434 & 542 & 640 \\
\hline 0.9 & 164 & 270 & 325 & 415 & 527 & 618 \\
\hline 1.0 & $160)$ & 264 & 319 & 4012 & 514 & 596 \\
\hline $1 \cdot 1$ & 157 & 258 & 313 & 398 & 5013 & 580 \\
\hline 1.2 & 154 & 255 & 305 & 392 & 490 & 568 \\
\hline $1 \cdot 3$ & 153 & 253 & 297 & 388 & 480 & 558 \\
\hline 1.4 & 150 & 250 & 290 & 383 & 470 & 546 \\
\hline
\end{tabular}

$\left.\left.T_{\mathrm{m}}=2800\right) \mathrm{K} ; T_{\mathrm{n}}=600\right) \mathrm{K} ; P_{\mathrm{m}}=2.5 \mathrm{~atm}$

rate of $1.2 \mathrm{~kg} / \mathrm{s}$. It can also be seen that core velocity at the inlet is approximately proportional to mass flow rate. However, for larger values of $x$ there is a deviation and this is due to the increase of the boundary layer. For example at $x=0 \cdot 1 \mathrm{~m}$ the velocity is $175 \mathrm{~m} / \mathrm{s}$ at $G=0.3 \mathrm{~kg} / \mathrm{s}, 350 \mathrm{~m} / \mathrm{s}$ at $G=0.6 \mathrm{~kg} / \mathrm{s}$ and $702 \mathrm{~m} / \mathrm{s}$ at $G=1.2 \mathrm{~kg} / \mathrm{s}$. There is only $(0.3 \%$ deviation from linearity. On the other hand, at $x=1.4 \mathrm{~m}$ the velocity is $150 \mathrm{~m} / \mathrm{s}$ at $0.3 \mathrm{~kg} / \mathrm{s}, 290) \mathrm{m} / \mathrm{s}$ at $0.6 \mathrm{~kg} / \mathrm{s}(3 \%$ deviation $)$ and $546 \mathrm{~m} / \mathrm{s}$ at $1.2 \mathrm{~kg} / \mathrm{s}(9 \%$ deviation from linearity $)$.

3.1c Pressure and friction coefficient along the channel: Figure 7 gives a plot of typical pressure and friction coefficient along the channel length. The friction coefficient is defined as

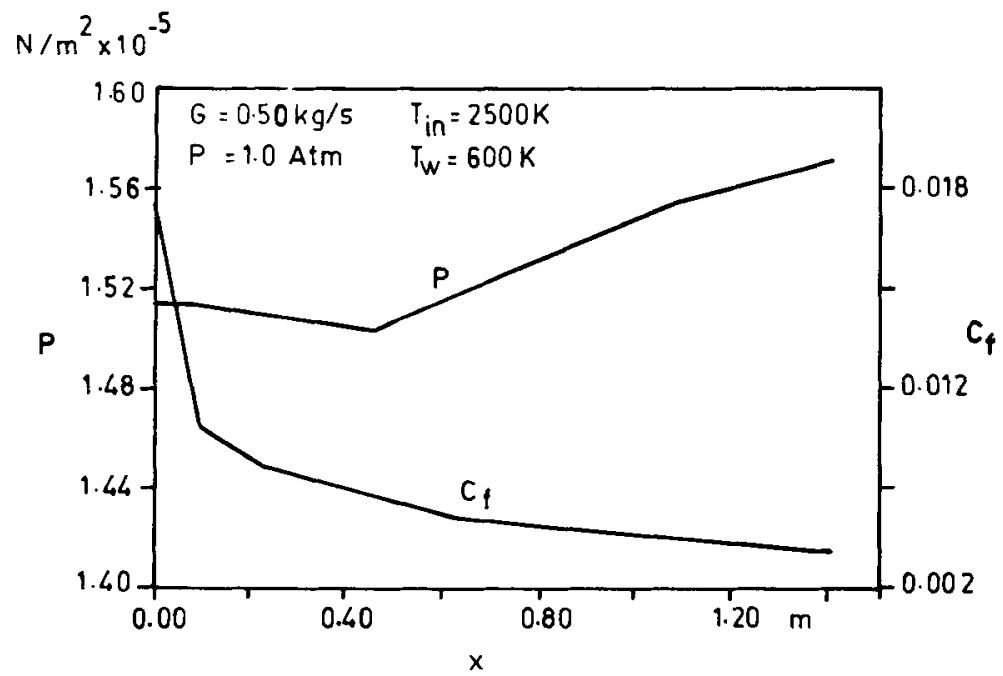

Figure 7. Pressure and friction coefficient along the channel. 


$$
C_{f}=\tau /\left(0 \cdot 5 \rho_{C} U_{C}^{2}\right),
$$

$\rho_{C}$ and $U_{C}$ are density and velocity in the core. $\tau$, the frictional force per unit area at the wall is given by

$$
\tau=\left.\mu \frac{\mathrm{d} U}{\mathrm{~d} y}\right|_{y=0},
$$

where $\mu$ is the viscosity. Since there is no MHD force in the ZINC channel the only retarding force in the channel is the frictional force.

An increase in the pressure can be seen after $x=0.475 \mathrm{~m}$ and is again due to the increase in the cross-section of the channel. An increase in the cross-section decreases the velocity which in turn increases the pressure.

We also see that the friction coefficient is very large at the inlet and decreases along the channel. This arises because of the increase in the boundary layer thickness along $x$.

In figure 8 the pressure profiles for various inlet pressures and mass flow rates are plotted for combustion plasma. We see that at low mass flow rates the pressure profile is less sensitive to the variation of cross-sectional area.

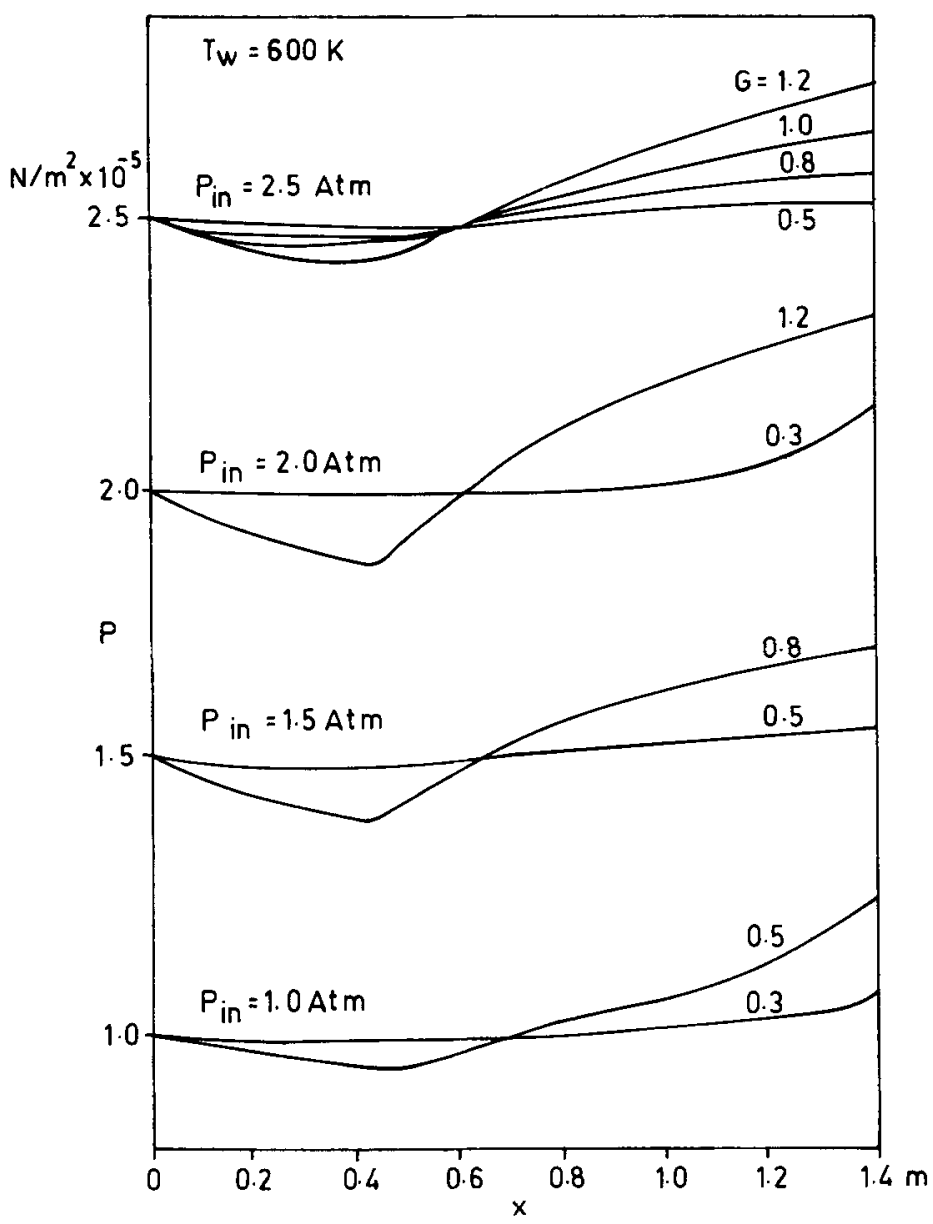

Figure 8. Pressure distribution along the channel for combustion plasma. 


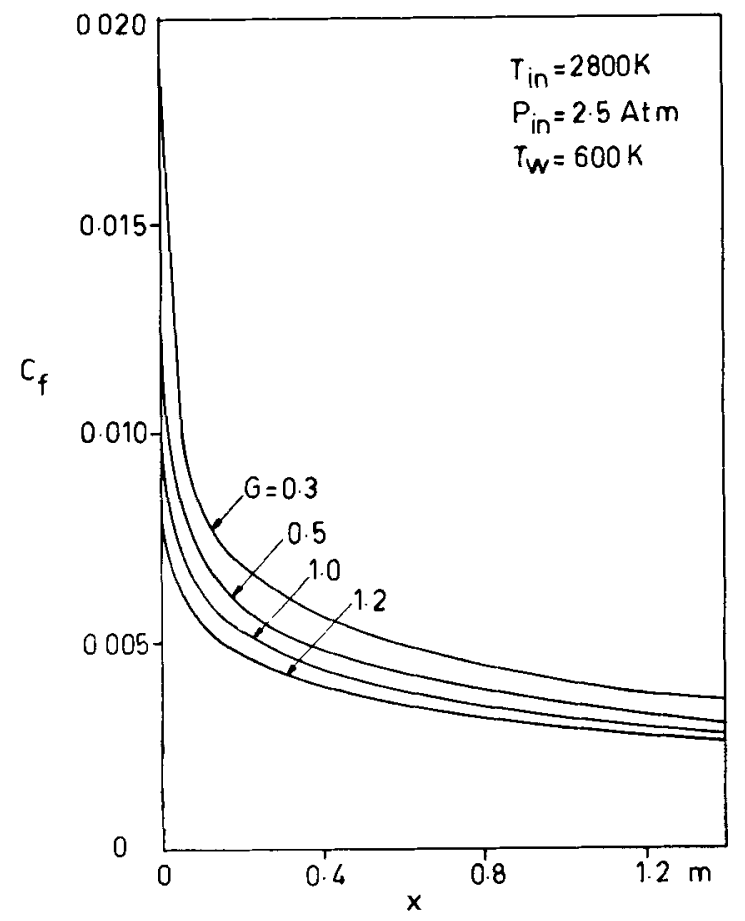

Figure 9. Friction coefficient along thc channel for varying mass flow rates for combustion plasma.

In figure 9 the friction coefficient along the channel is plotted for various mass flow rates for a given inlet pressure and temperature. The graph shows a decrease of friction coefficient for a higher mass flow rate along the channel. This is because of the following reason. We have the friction coefficient given by (17). At larger mass flow rates $\tau$ sharply increases due to the increase in the velocity gradient at the wall. However, at larger mass flow rates the denominator in (17) i.e. $0 \cdot 5 \rho_{C} U_{C}^{2}$ also increases sharply. Thus, the net effect is the decrease in the friction coefficient. Typical numerical values of $\rho_{C} U_{C}, \tau$ and $C_{f}$ at a given $x(=0.7 \mathrm{~m})$ for different mass flow rates are shown in table 3 . It is also found that the friction coefficient profile is independent of pressure. To know how the friction coefficient calculated exactly from the boundary layer profile differs from the empirical relation, the two graphs are compared in figure 10. The empirical relation is taken as (Schlichting 1968)

$$
C_{f}=0.0576 R_{e}^{-0.2}
$$

Table 3. Effect of mass flow rate on $\tau$ and $C_{f}$

\begin{tabular}{cccccc}
\hline $\begin{array}{c}G \\
(\mathrm{~kg} / \mathrm{s})\end{array}$ & $\begin{array}{c}\rho_{C} \\
\left(\mathrm{~kg} / \mathrm{m}^{3}\right)\end{array}$ & $\begin{array}{c}U_{C} \\
(\mathrm{~m} / \mathrm{s})\end{array}$ & $\begin{array}{c}\frac{1}{2} \rho_{C} U_{C}^{2} \\
\left(\mathrm{~kg} / \mathrm{ms}^{2}\right)\end{array}$ & $\begin{array}{c}\tau \\
\left(\mathrm{N} / \mathrm{m}^{2}\right)\end{array}$ & $C_{f}$ \\
\hline 0.3 & 0.296 & $171 \cdot 0$ & $4.35 \times 10^{3}$ & 20.33 & 0.0046 \\
0.6 & 0.298 & $340 \cdot 0$ & $34.5 \times 10^{3}$ & 130.91 & 0.0038 \\
1.2 & 0.303 & $660 \cdot 0$ & $65.0 \times 10^{3}$ & $208 \cdot 0$ & 0.0032 \\
\hline$P_{\text {in }}=2.5 \mathrm{~atm} ;$ & $T_{\text {in }}=2800 \mathrm{~K} ; T_{n^{\prime}}=600 \mathrm{~K}$. & &
\end{tabular}




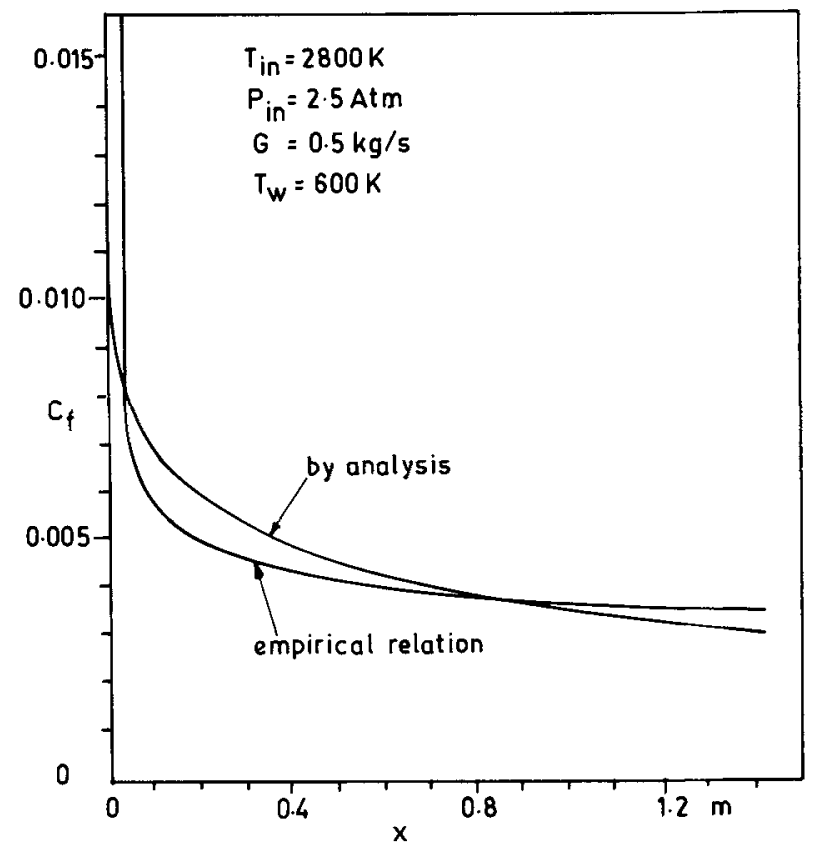

Figure 10. Comparison of friction coefficient profile with the empirical relation for combustion plasma.

where $R_{e}$ is the Reynold's number in the core. This is the relation that is commonly used when explicit boundary layer analysis is not done. This relation is valid only for zero pressure gradient turbulent flows. It can be seen that, there is a significant deviation between the exact calculation and the empirical value. This confirms the necessity for solving boundary layer equations explicitly.

3.1d Velocity profiles across the boundary layer and boundary layer growth: In figure 11 a typical velocity profile across the boundary layer at various points along

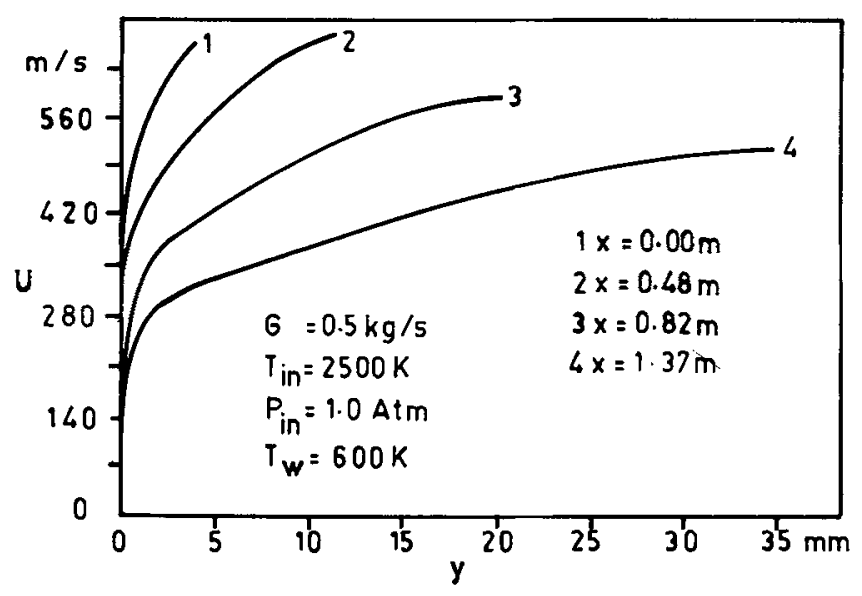

Figure 11. Velocity profiles across the boundary layer. 
the channel are shown for combustion plasma. Profiles are less steep at higher values of $x$. This is because of the growth of the boundary along $x$, the velocity across the channel in the core region remains constant. The frictional force due to the wall is proportional to the velocity gradient at the wall which in turn is related to boundary layer thickness. This explains why the friction coefficient is larger at smaller values of $x$.

The boundary layer grows along the length of the channel. In fact the analysis conducted here confines to the region where the flow is not fully developed. In figure 12, a typical boundary layer growth is plotted for different mass flow rates. We see that for larger mass flow rates the boundary layer is thinner. The reason is that the velocity is large at higher mass flow rates, which effectively decreases the boundary layer thickness. The empirical relation for boundary layer thickness is

$$
\delta_{\mathrm{em}}=0 \cdot 37 \times R_{c}^{-(0.2}
$$

Also we see that the empirical relation matches fairly well with the exactly calculated one. However, when there are MHD terms as well as steep pressure gradients it deviates substantially (Satyamurthy 1983).

\subsection{Thermal parameters}

3.2a Temperature and heat flux: In figure 13, core temperature and heat flux along the channel are plotted for a typical set of inlet parameters. The core temperature

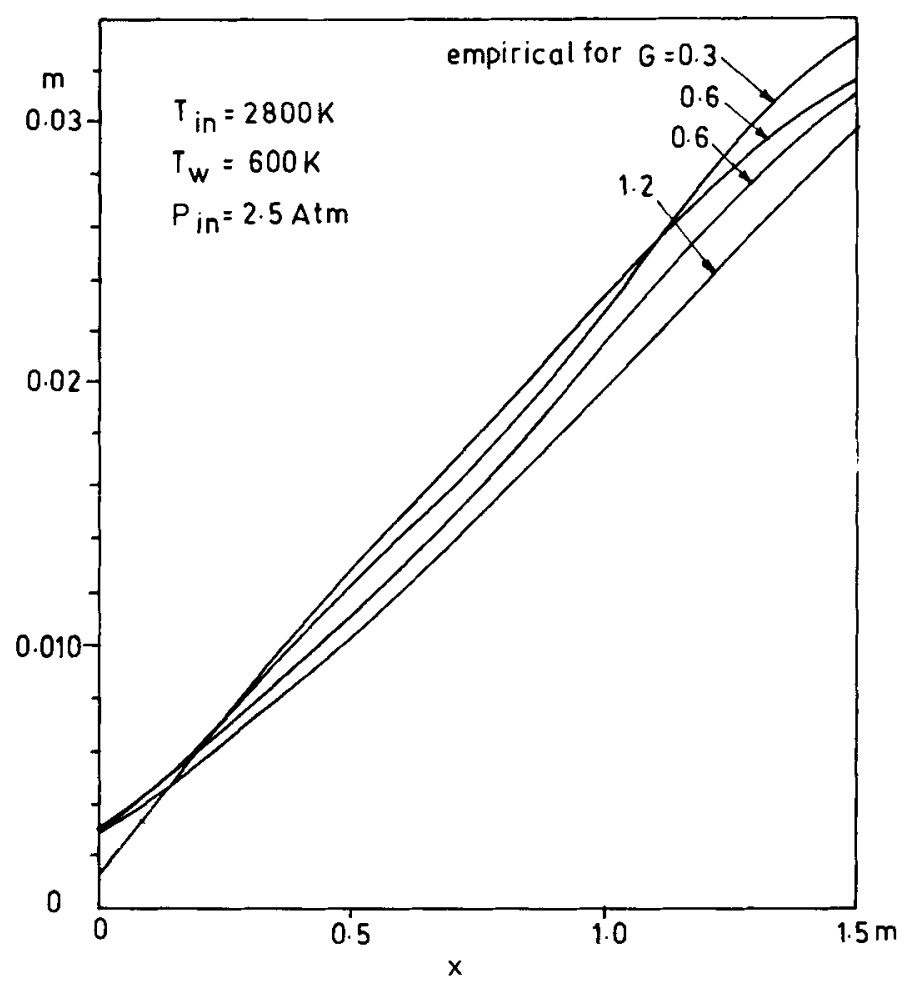

Figure 12. Boundary layer thickness along the channel. 


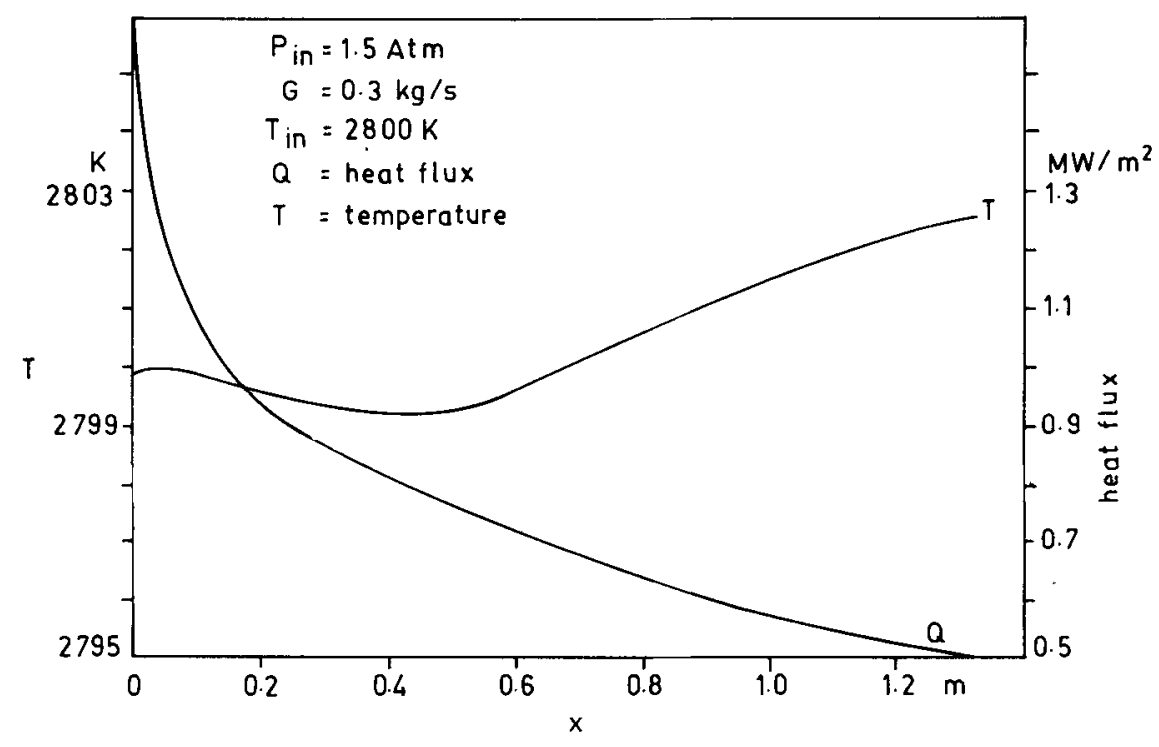

Figure 13. Temperature and heat flux along the channel (temperature is shown on an expanded scale).

increases slightly after $x=0.475 \mathrm{~m}$. This is because of the decrease in core velocity after the nozzle spacer (figure 6). We have from the enthalpy equation in the core given by (2),

$$
H=h+\frac{1}{2} U_{C}^{2}=\text { constant, }
$$

where $h$ is the static enthalpy. We see that as $U_{C}$. decreases, $h$ increases which in turn increases the static temperture of the plasma. In figure 13 heat flux along the channel is also plotted. The sharp fall in heat flux along the channel is due to the increase in thermal boundary layer thickness.

Figure 14 shows the graph of heat flux along the channel for various mass flow rates for a given inlet pressure and temperature. The heat flux increases sharply with increase in mass flow rate. This is due to decrease in thermal boundary layer thickness with increasing mass flow rate. The effect of the core temperature on heat flux is plotted in figure 15 for a given inlet pressure and mass flow rate. As expected, at higher core temperatures the heat flux increases. In figure 16 the effect of pressure on heat flux is plotted. We see that heat flux is less sensitive to pressure. However, at higher pressures the heat flux decreases. This is because of the decrease in thermal conductivity at higher pressure.

3.2b Temperature profiles across the boundary layer: The temperature profiles decide both the electrical conductivity profiles and the heat flux to the walls. The electrical conductivity profiles across the boundary layer decide the overall near-electrode drop, which in turn decides the performance of the MHD generator. Detailed analysis on this aspect is beyond the scope of the present study. Temperature profiles across the boundary layer at different $x$ values are shown in figure 17. As can be seen, due to the thinner boundary layer near the entrance of the channel, temperature boundary layers are steeper. Heat flux at the wall is related to temperature as 


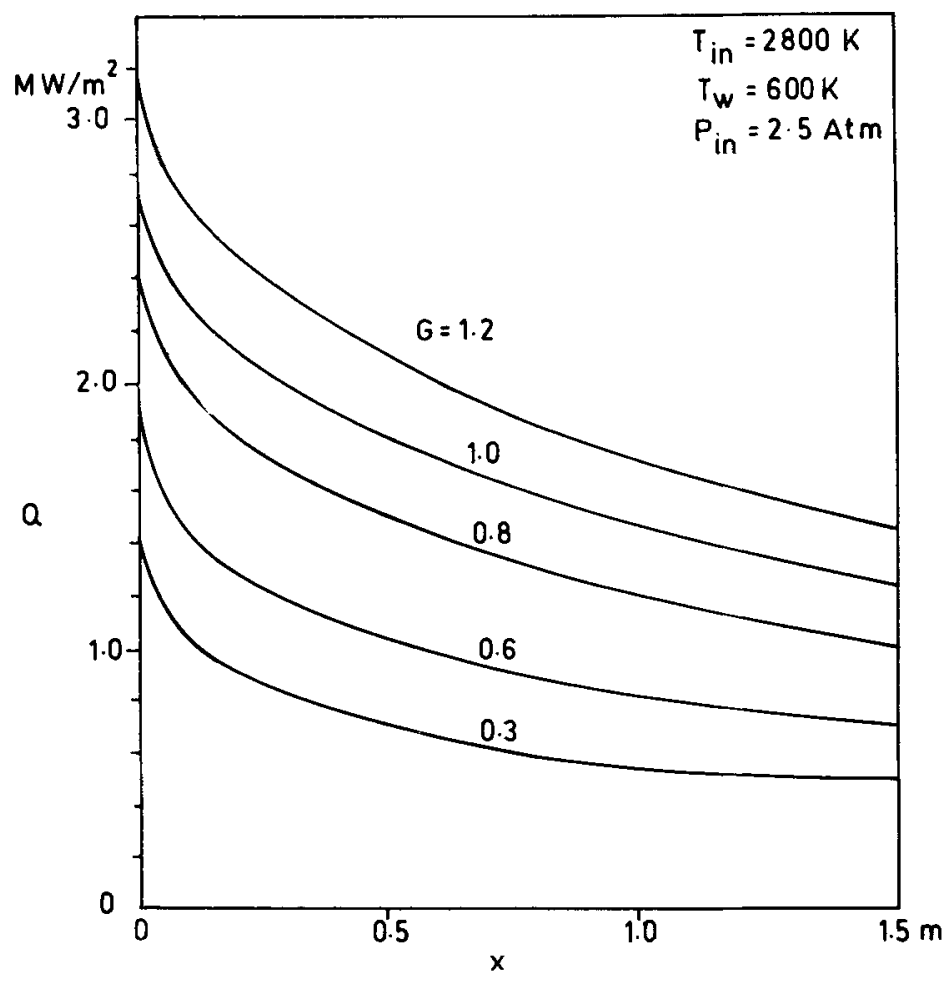

Figure 14. Heat flux along the channel for various mass flow rates for combustion plasma.

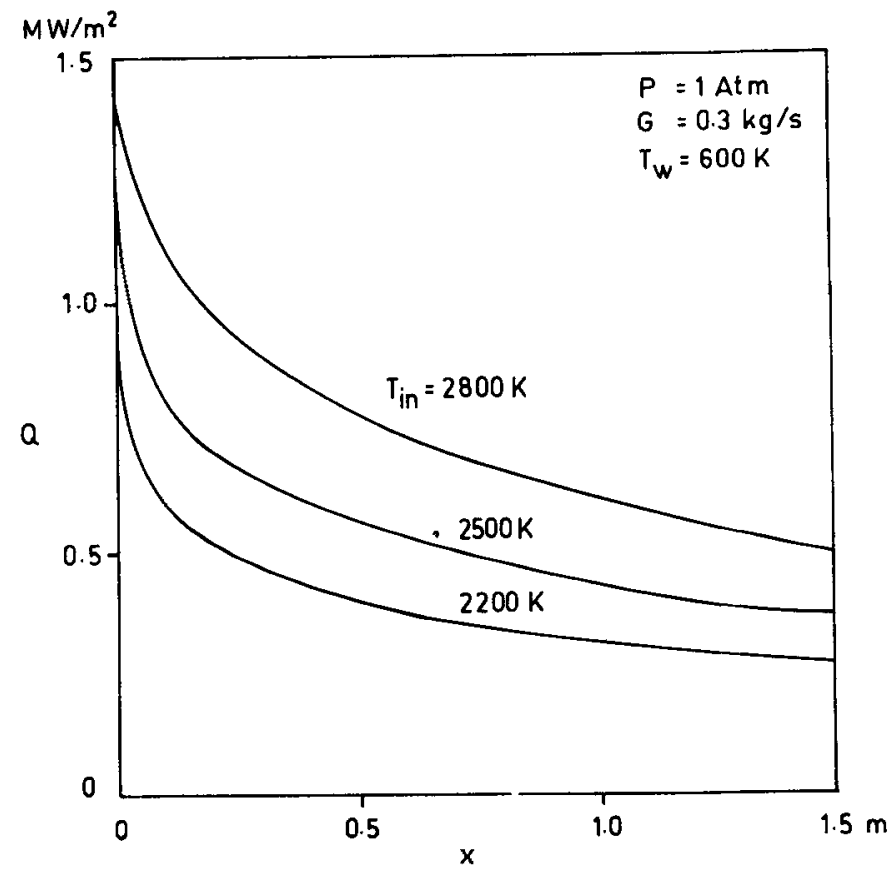

Figure 15. Effect of temperature on heat flux along the channel for combustion plasma. 


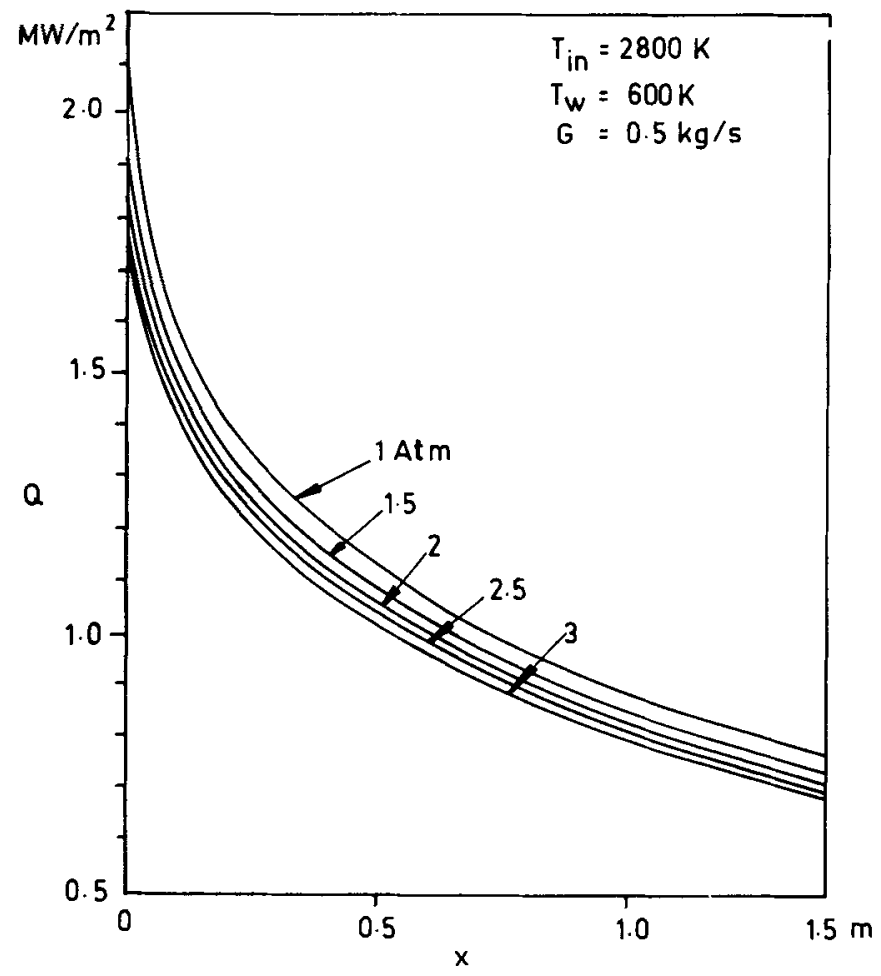

Figure 16. Heat flux along the channel for different pressures for combustion plasma.

$$
Q=\left.K \frac{\partial T}{\partial y}\right|_{y=0}=\left.K \frac{\partial T}{\partial z}\right|_{z=0},
$$

where $K$ is the thermal conductivity. For thinner boundary layers the gradient is larger and because of this heat fluxes are larger for the smaller $x$-values (figure 12).

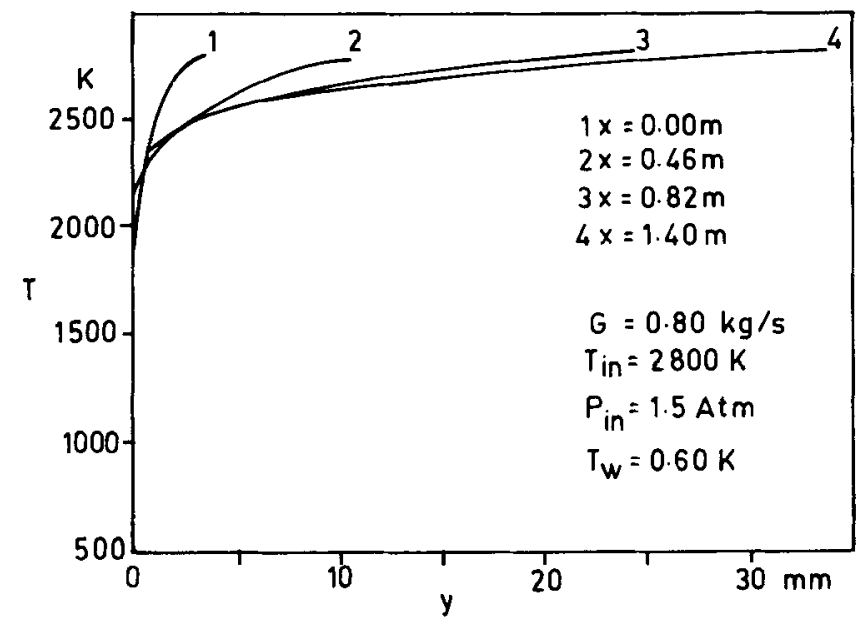

Figure 17. Temperature profiles across the boundary layer. 
3.3 Comparison of heat flux and friction coefficient between combustion plasma and hot air

In figure 18 heat flux and friction coefficients are compared for combustion plasma and hot air. As can be seen, the friction coefficient for air and combustion plasma are almost equal. This is because the density and coefficient of viscosity of air and combustion plasma are nearly the same (Das 1979).

However, there is an appreciable difference in the heat fluxes of the two gases. This is due to the larger thermal conductivity of combustion plasma compared to that of air (Das 1979).

\subsection{Comparison with experimental results}

The shakedown tests of the MHD facility at Tiruchirapalli were carried out during 25-28 March 1985. A limited number of plasma measurements and other thermal measurements were carried out. The heat fluxes were estimated on the basis of thermal data. The results of the two regimes of operation have been analysed.

Pressure at the inlet $=1$ atm

Mass flow rate $\quad=0.316 \mathrm{~kg} / \mathrm{s}$

$\begin{array}{lll}\text { Working media } & \begin{array}{l}\text { Regime 1 } \\ \text { Hot air }\end{array} & \begin{array}{l}\text { Regime 2 } \\ \text { Combustion products }\end{array} \\ \begin{array}{l}\text { Measured temperature } \\ \text { at the inlet }\end{array} & 1560 \mathrm{~K} & 2073 \mathrm{~K}\end{array}$

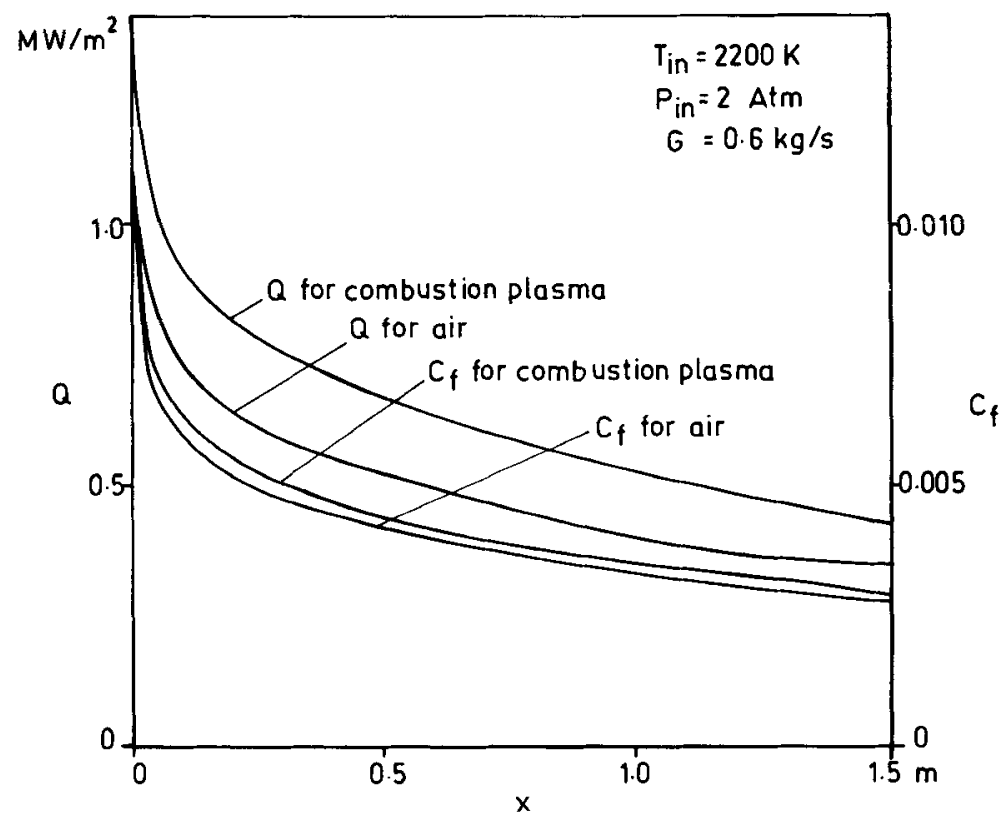

Figure 18. Heat flux and friction coefficient along the channel for combustion plasma and air flows. 
The measured heat fluxes at two ports are compared with theoretical predictions in figure 19.

The pressures were measured at the inlet and exit of the channel. The pressure drop was negligible both for combustion plasma and air at the above mass flow rates (the drop was less than the measurement accuracy of the instruments used in the first run of experiments). This compares well with the calculated pressure drops. For $G=0.3 \mathrm{~kg} / \mathrm{s}$, it can be seen from figure 8 that, for $1.5 \mathrm{~m}$ of length of the channel the pressure change is very small $(0.03 \mathrm{~atm})$ which is much less than the measurement accuracy.

The present results correspond to the first experimental run of the MHD plant. Based on these observations, additional instrumentation with sufficient accuracy and increased number of measurement points is being introduced at the pilot plant.

\section{Summary and conclusions}

In this paper quasi-three-dimensional analysis of a diverging rectangular channel is carried out. The purpose of this geometry is to simulate the gasdynamic and thermal characteristics of the MHD power generator.

The model used is a coupled core-boundary layer flow. The gas is assumed to be in thermodynamic equilibrium and the flow is taken to be steady, compressible and turbulent. The gas is assumed to be nonideal and all the transport and thermodynamic parameters are taken as functions of pressure and temperature.

The analysis is confined to $1.5 \mathrm{~m}$ from the entrance of the channel where the channel undergoes the maximum gasdynamic (frictional force) and thermal stresses (heat fluxes). The coupled core-boundary layer equations are solved by the Patankar and Spalding numerical technique. The behaviour of core velocity, core temperature, pressure profiles, friction coefficient and heat flux for different core temperatures, mass flow rates and inlet pressures are analysed. The results of the

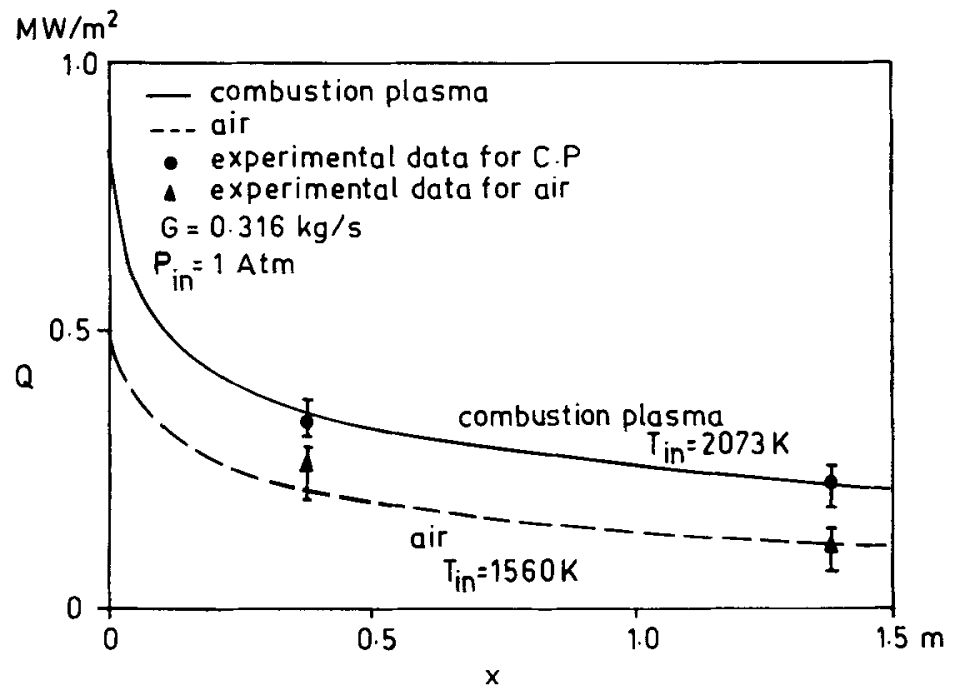

Figure 19. Comparison with experimental results. 
detailed studies carried out on the ZINC MHD channel can be summarised as follows:

(1) At low mass flow rates and low inlet pressures, the pressure drop across the channel is quite small.

(2) For a given inlet pressure and temperature, the friction coefficient decreases with increase in the mass flow rate. Also it is found that empirically predicted values deviate significantly from explicitly calculated values.

(3) The heat flux increases strongly with the increase of mass flow rate. However, it is less sensitive to the increase in the pressure. Due to decrease in the thermal conductivity at higher pressure, there is a slight decrease in the heat flux.

(4) Experimentally measured heat flux and pressure drop across the channel match the theoretically predicted values based on the model developed in this paper quite well.

\section{References}

Cebeci T 1974 Analysis of turbulent boundary layers (New York: Academic Press)

Das A K 1979 Study of thermodynamic and transport properties of combustion plasmas. Ph.D. thesis, Bombay University

Patankar S V, Spalding D B 1967 Heat and mass transfer in boundary layers (London: MorganGramphian)

Rohatgi V K, Venkatramani N 1981 Recent advances in MHD generation, BARC Report

Satyamurthy $\mathrm{P} 1983$ Analysis of a combustion driven MHD generator using a quasi-three-dimensional model, Ph.D. thesis, Bombay University

Satyamurthy P, Venkatramani N, Rohatgi V K 1982 Energy Convers. Manag. 22: 243-250

Schlichting H 1968 Boundary layer theory (New York: McGraw Hill) 